\title{
A MODA RETRÔ E A FASCINAÇÃO COM O NAZISMO: LACOMBE LUCIEN E A CRÍTICA DE CINEMA FRANCESA
}

\author{
The retro fashion and fascination with Nazism: \\ Lacombe Lucien and the French film criticism
}

La moda retro y la fascinación con el nazismo:

Lacombe Lucien y la crítica de cine francesa

\author{
Margarida Maria Adamatti \\ Doutora em Meios e Processos Audiovisuais (ECA-USP), \\ pesquisadora de pós-doutorado (PNPD/CAPES) e \\ professora do Programa de Pós-Graduação em Imagem e Som da \\ Universidade Federal de São Carlos (UFSCar) \\ mmadamatti@hotmail.com
}

\section{Resumo}

Quando Louis Malle escolheu colocar nas telas o tema da cooptação do jovem camponês Lacombe Lucien (1974) em vez de frisar a resistência francesa, ele adentrou num campo minado com a crítica de cinema da revista Cahiers du Cinéma. Num contexto de crescente politização, a publicação dedicou ao filme artigos em torno das teorias da enunciação, da semiologia, da criação de estereótipos e, especialmente, em torno da onda retrô. Por mais de um ano, o cineasta foi acusado de estar fascinado pelo nazismo ao invés de denunciá-lo. $\mathrm{O}$ assunto tabu para os franceses acendeu um debate intenso entre Pascal Bonitzer, Serge Daney, Pascal Kané, Serge Toubiana, Michel Foucault e Marc Ferro, que analisamos nesse artigo para ampliar a compreensão da metodologia da crítica de cinema francesa daquele momento.

Palavras-chave: Crítica cinematográfica. Lacombe Lucien. Cahiers du Cinéma.

\begin{abstract}
When Louis Malle chose to put on screen the theme of the young peasant Lacombe Lucien (1974) cooptation instead of stressing the French resistance, he entered a minefield against Cahiers du Cinéma film criticism. In a context of increasing politicization, the magazine dedicated to film articles around the theories of enunciation, semiotics, of stereotypes creation, and especially around the retro wave. For over a year, the director was accused of being fascinated by Nazism rather than report it. The taboo subject for French sparked an intense debate between Pascal Bonitzer, Serge Daney, Pascal Kané, Serge Toubiana, Michel Foucault and Marc Ferro, that we analyzed in this article to expand the understanding of the critical methodology of French film criticism at that time.
\end{abstract}


Key words: Film criticism. Lacombe Lucien. Cahiers du Cinéma.

\section{Resumen}

Cuando Louis Malle eligió colocar en las pantallas el tema de la cooptación del joven campesino Lacombe Lucien (1974) en vez de frisar la resistencia francesa, se adentró en un campo minado con la crítica de cine de la revista Cahiers du Cinéma. En un contexto de creciente politización, la publicación dedicó a la película artículos en torno a las teorías de la enunciación, la semiología, la creación de estereotipos y especialmente en torno a la onda retro. Durante más de un año, el cineasta fue acusado de estar fascinado por el nazismo en lugar de denunciarlo. El tema tabú para los franceses encendió un intenso debate entre Pascal Bonitzer, Serge Daney, Pascal Kané, Serge Toubiana, Michel Foucault y Marc Ferro, que analizamos en este artículo para ampliar la comprensión de la metodología de la crítica de cine francesa de aquel momento.

Palabras clave: Crítica cinematográfica. Lacombe Lucien. Cahiers du Cinéma.

\section{INTRODUÇÃO}

Crítico da revista Cahiers du Cinéma, Louis Malle começou sua carreira como assistente de direção de Robert Bresson. Alguns de seus filmes abriram polêmicas em torno do erotismo. Os amantes (1958) foi censurado no Brasil por conter uma insinuação de sexo oral, enquanto Um sopro no coração (1971) tratava de incesto e Pretty Baby (1978) de prostituição infantil. O lançamento de Lacombe Lucien (1974) não fugiu à regra e colocou em foco o relacionamento de poder e sedução entre um jovem camponês nazista e uma moça judia. Esta não era a única polêmica inaugurada pelo filme, que girava em torno da colaboração durante a Ocupação. Anos depois, Louis Malle voltou ao tema tabu para os franceses em Adeus Meninos (1987) e escolheu representar de novo o delator na figura de um jovem pobre.

Diferente de Adeus meninos, o colaborador de Lacombe Lucien procura no nazismo um reconhecimento social que sua pouca idade e modos rústicos não lhe permitem ter. Com medo da denúncia e prisão iminente, uma refinada família judia é obrigada a aceitar a presença desse jovem camponês em sua casa. Em pouco tempo, Lucien passa a viver à custa do famoso alfaiate e se envolve sexualmente com sua filha, numa relação ambígua entre dominação, opressão e sedução. Ao longo do filme, o relacionamento sofre alguns contrapesos. No final, a bela France consegue convencer Lucien a incorporar seu sonho de 
evasão e fuga para a Espanha. É nesse momento que o componente da erotização e de humanização do jovem soldado entra em cena. Da rigidez inicial, o personagem é mostrado pela primeira vez feliz e sorridente ao lado de France na paisagem rural francesa. Essa brecha abre uma indagação ao espectador quando ele é surpreendido pela notícia da execução do personagem "real" no final da guerra. Lucien não é totalmente mau porque ama a moça judia e a livrou do campo de concentração? Mereceria o perdão porque salvou sua vida? Não só esse aspecto do filme, mas a própria construção do personagem de Lucien, foi tema de diversos atritos com os críticos da revista Cahiers du Cinéma, porque o ponto de vista adotado possibilitaria humanizar um colaborador. Além disso, haveria no filme uma fascinação com o nazismo e uma fuga da perspectiva política, através de componentes de erotização.

A polêmica surgia porque Louis Malle entrava num tema constrangedor para os franceses e trazia outro olhar sobre a posição deles durante a Ocupação. Não era a primeira vez que um filme francês colocava em questão o papel dos franceses durante a Segunda Guerra Mundial. Em 1969, Marcel Ophüls realizou o documentário A dor e a piedade, demonstrando através dos depoimentos o quanto as fronteiras entre resistência e aproximação com os alemães foram tênues. Portanto, não era a temática em si da cooptação que mais incomodava, mas o recurso conjunto à ficção e à erotização do nazismo como estratégia vindoura para atingir o grande público. Naquele momento, a representação do nazismo pela erotização era vista em Cahiers du Cinéma como um perigo político por causa do componente de sedução, como veremos ao longo desse artigo. Interessa-nos demonstrar como a revista constrói sua argumentação a partir de critérios conceituais externos ao campo do cinema, num período de crescente politização da atividade crítica. $\mathrm{O}$ artigo, portanto, propõe a discussão desses métodos de análise fílmica aplicados a Lacombe Lucien, porque a releitura marxista, a discussão dos estereótipos e da semiologia trouxe contribuições enquanto formas de análise.

Existe uma lacuna na bibliografia sobre Cahiers que se refere à aplicação prática desses conceitos nos comentários sobre os filmes. Autores como Jim Hilliers, Nick Brown e David Wilson ocupam-se das fases gerais da revista, sem demonstrar como essas noções teóricas eram utilizadas na análise fílmica propriamente. Portanto, nosso interesse é demonstrar a correlação entre os conceitos teóricos e sua aplicação em Lacombe Lucien. Pela extensão do artigo, não nos deteremos na análise da obra propriamente. Não procuramos na 
materialidade fílmica uma comprovação dos comentários dos críticos de cinema, nem tampouco pretendemos avaliar a recepção completa de Lacombe.

Depois do Maio de 1968, a revista Cahiers du Cinéma assumiu uma posição mais teórica e militante com o desejo de intervir na sociedade através dos textos. Com a crescente politização da produção cinematográfica ao redor do mundo, o cinema parecia um campo de luta e mudança social. Enquanto a ferramenta da mise en scène e o conceito de autoria entravam em decadência enquanto método (STAM, 2003), os estudos de linguística, a releitura da teoria marxista e o estruturalismo deslocavam a discussão da crítica de cinema para a perspectiva política. Num ambiente de crise de paradigmas, Cahiers du Cinéma tornouse maoista em 1971, e pensava a produção intelectual como uma ferramenta de mudanças sociais (HILLIERS; BROWNE, 1996, WILSON, 2000).

A análise da obra de Louis Malle em Cahiers pode ser tomada como exemplo da nova tendência teórica da revista. Lacombe é objeto de uma densa coletânea de textos entre 19741975 e de comentários comparativos em anos posteriores. Em voz uníssona, a publicação atacou seu ex-crítico e abordou diversos ângulos do filme. Pascal Bonitzer e Serge Daney analisaram Lacombe em pormenores. Mas também Pascal Kané e Serge Toubiana participaram compondo excertos teóricos sobre o tema. Além deles, Cahiers convidou Michel Foucault e Marc Ferro para uma entrevista. No ápice da discussão havia questões de fundo teórico, como a construção da enunciação no cinema, a teorização do uso do estereótipo nos filmes, o papel da naturalização e da ideologia na representação do nazismo e as novas tendências do cinema francês. $\mathrm{O}$ foco de Cahiers era o cinema político e a forma adotada por Louis Malle. No centro da polêmica estava a estética enquanto fuga do político.

Se os conceitos teóricos são utilizados de forma concomitante nos textos, dividiremos a argumentação da revista em subitens, para observar a metodologia da revista e a aplicação das teorias apresentadas: 1 . Teoria da enunciação e a função da crítica de cinema; 2 . A cena do esparadrapo e a psicologia do personagem; 3. Estereótipos e a preferência pelo naturalismo no cinema; 4. A moda retrô do cinema francês; 5. O outro lado da moeda: a dissonância aplicada por Michel Foucault e Marc Ferro.

\section{DESENVOLVIMENTO}




\subsection{Teoria da enunciação e a função da crítica de cinema}

O debate sobre Lacombe Lucien não começa pela análise interna. Antes, a revista aplica a semiologia ao campo do cinema para discutir o mecanismo de enunciação e o funcionamento do estereótipo na produção francesa dos anos setenta. Pascal Bonitzer (1974) abre o debate. Mas antes de decompor uma cena de Lacombe, o crítico expõe suas ferramentas de trabalho e quais são os objetivos da crítica de cinema. Na tipologia apresentada, se vê claramente quanto os critérios ideológicos incidem no texto de Cahiers. Enquanto método de análise, o artigo inicia com a diferença entre a denotação e a conotação como chave explicativa para o funcionamento da crítica de cinema.

Bonitzer parte de uma definição muito próxima a de Roland Barthes para atacar o uso da denotação na crítica de cinema. O linguista francês via a denotação como um "mito científico". Nesses casos, as frases são escritas como se trouxessem em si uma "origem e verdade" (BARTHES, 1977, p. 74). É esse o pressuposto teórico do artigo de Bonitzer, que, indiretamente, adapta a proposta de Roland Barthes de desmistificar a linguagem e a submeter a alguma instância superior. Para o autor, quando a crítica de cinema só leva em conta a denotação, ela se torna incapaz de analisar os enunciados e o valor das mensagens. Voltada somente ao conteúdo do filme, nesses casos, o texto cairia numa "cilada", porque toda forma de denotação implica em uma ideologia. Por causa desses motivos, tanto a denotação quanto a crítica conteudística são ineficazes na "luta ideológica", segundo o autor, porque elas só se preocupam em manter a ordem social. Esse preâmbulo teórico do artigo de Pascal Bonitzer é o eixo fundamental para acompanhar a argumentação de Cahiers sobre Lacombe. Além disso, o comentário possibilita avaliar um tipo de genealogia dos métodos da crítica de cinema, com origem em autores que advém de outros campos de análise, como Roland Barthes.

A condenação à denotação tem um objetivo claro no pensamento de Cahiers daquele momento. A proposta da revista era deixar as conotações falarem, sem bloquear os significados ao nível da denotação. Graças a esse trabalho, o crítico de cinema acrescenta sentidos não evidentes e sublinha o conteúdo latente das cenas. Esse elogio à conotação na crítica significa mostrar com todas as letras ao público que "a verdade é um processo de construção". Mais uma vez há uma similitude com Roland Barthes (1977, p. 73-74) que definia o trabalho intelectual como o de fazer suspeitar de qualquer enunciado. $\mathrm{O}$ autor 
propunha realizar um "escalonamento de linguagem" como exemplo de uma "ciência inédita", encarregada de abalar as instâncias habituais da expressão, da verdade e da realidade. Cahiers poderia ser incluída na denominação bartheana dos "maníacos do segundo grau", isto é, os que rejeitam a denotação e só toleram as linguagens encarregadas de testemunhar "o poder do desencaixe".

Se parte considerável do texto diferencia a denotação e a conotação na crítica de cinema, o intuito é demonstrar o funcionamento da enunciação e a "armadilha ideológica" de Lacombe Lucien. Esse argumento será a linha de base para o entendimento dos artigos subsequentes sobre Lacombe. Bonitzer procura trazer aos leitores qual era o sentido conotado do personagem principal. A estratégia passa pela preferência de Malle em realçar a denotação, isto é, a psique de Lucien. Esse desvio esconde uma mensagem e um conteúdo latente que:

revela ao mesmo tempo o sistema pelo qual o filme responde: cegar, barrar, atrapalhar a denotação do comportamento de Lucien, de tal forma que este comportamento denote bem o fascismo, mas conota também outra coisa, e esta outra coisa, em princípio indefinível (a psiqué de Lucien) que traz em última instância o sentido (BONITZER, 1974) ${ }^{1}$.

Se o comportamento de Lucien denota bem o fascismo, para Bonitzer o intuito de Louis Malle é esconder outras conotações, como veremos. Não só Bonitzer, mas os demais artigos sobre Lacombe em Cahiers condenam que o comportamento do jovem camponês seja explicado apenas pela psicologia, isto é, pelo sentido denotado. Segundo a revista, essa foi a forma escolhida por Louis Malle para fugir de uma perspectiva política do nazismo. Portanto, Bonitzer converte a diferente entre denotação e denotação em método de análise fílmica para procurar pelos sentidos latentes do personagem. Dessa forma, a adaptação de Roland Barthes tornou-se um método de análise útil à compreensão dos mecanismos de significação do filme, contribuindo com o debate.

\subsection{A cena do esparadrapo e a psicologia do personagem}

\footnotetext{
${ }^{1}$ Todas as traduções do artigo são de nossa autoria. 
Os comentários acima descritos sobre a diferença entre denotação e conotação constituem uma espécie de introdução ao artigo de Bonitzer (1974) sobre Lacombe Lucien. De todos os artigos publicados em Cahiers sobre o filme, a análise da cena do "esparadrapo" de Pascal Bonitzer é de longe a mais relevante. Na fase maoista da revista, nem sempre a análise detalhada das cenas era uma prioridade; nesse sentido resta destacar que foi a única sequência analisada de Lacombe em pormenores. O objetivo de Bonitzer foi observar como a construção do enunciado aparece na temática do filme, ocultando o sentido conotado. Isto é, o intuito do autor foi o de discutir as formas de inserir um enunciado político no cinema.

Para Bonitzer, a cena do esparadrapo é o centro da representação política do filme. Num ambiente de tortura, Lucien é encarregado de vigiar um preso. No cativeiro, o prisioneiro amordaçado tenta estabelecer algum tipo de contato humano com Lucien. Sem conseguir, ele procura apelar aos "bons" sentimentos "franceses". O colaborador nazista irrita-se. Ao pedido de soltura, Lucien responde apenas que não gosta de ser tratado por "tu". Para encerrar de vez a conversa, Lucien coloca um esparadrapo na boca do preso. Depois preenche o contorno dos lábios com um batom. O que aborrece Lucien não é exatamente o pedido de soltura, ao qual ele é indiferente, mas o tratamento informal do prisioneiro. Devido a pouca idade, Lucien, sempre de calcas curtas, procura a todo custo ser visto como autoridade. É esse o sentido que Louis Malle quer priorizar em detrimento do fator político, conclui o crítico. Para Bonitzer, a resposta de Lucien na forma da ação de tapar os lábios do prisioneiro não aprofunda o posicionamento político do colaborador, mas prefere realçar a psicologia do personagem, isto é, humanizar um "garoto" de calca curta que quer ser visto como "homem crescido".

De acordo com Pascal Bonitzer, a cena tem um "posicionamento político" "implícito" que revela o "procedimento narrativo do filme" para comunicar sentido e denotar o comportamento de Lucien. Nela, o prisioneiro age como "representante da demanda do espectador, preocupado com a inserção de Lucien na história”. Ele pede para o personagem demarcar sua posição política, mas aí reside a "esperteza" de Malle, e a "inocência" do prisioneiro. Segundo Bonitzer (1974), Lucien não responde ao nível do enunciado da demanda (me solte), mas ao nível da enunciação (porque você me chama por tu?).

Quando Lucien amordaça o prisioneiro, segundo Bonitzer, "este gesto não tem sentido político". Ele não diz respeito ao significado político (libertar ou não o prisioneiro), mas ao significante (chamar por tu). Como consequência, o espectador hesita entre muitos sentidos 
contraditórios da denotação. Na sequência, Bonitzer questiona se o comportamento do personagem seria sinônimo de infantilismo, ou de sua inconsistência política? Seria certa inocência ou um aborrecimento com a política? No filme, Lucien representa um jovem de "hoje", um pouco "contestatário" 2 , mas ao mesmo tempo "perverso":

As bizarrices de Lucien são bem explicáveis. A explicação, o sistema, a causa são a família: é uma causa implícita (não se enuncia, denota que Lucien procure um pai), o que é muito evidente. Em filigrana, mas uma conotação muito aparente, se coloca o drama de Lucien, sua verdade. Lucien é uma criança que procura o pai, uma presença e um discurso paterno. Sobre esse drama e essa verdade, a história, o imaginário político, a identidade política de Lucien, a Gestapo, a resistência, a denotação, não são mais que máscaras, acidentes, falsos semblantes. (...) A etiqueta política Lucien como fascista, colaborador, é também artificial e vazia como uma ficha de estado civil. Lucien é tanto e tão pouco nazista que Lacombe Lucien (BONITZER, 1974).

Ao desviar o tema da Ocupação para a busca de Lucien por uma figura paterna, Louis Malle se esquivaria do significado político. Esse é o principal ponto de atrito dos críticos de Cahiers em relação ao cineasta. Para Bonitzer, Malle prefere concentrar-se somente no significante e na preocupação neurótica de Lucien em ser uma autoridade. Essa construção faz o público hesitar entre vários sentidos contraditórios para entender o personagem. Ao encontrar um pai substituto no alfaiate judeu, o comportamento de Lucien passaria somente pela denotação e pela questão familiar. Por causa desse desvio do sentido político, Bonitzer vê uma história simplista, cuja única ferramenta de análise histórica é a psicologia. De acordo com o crítico, não é por coincidência que Lucien se tornou delator e entrou para a Gestapo. A culpa seria dos resistentes que negaram o pedido do garoto de entrar para a Resistência, logo no início do filme. Dessa forma, Bonitzer vê um sentido político oculto no filme, que é a forma escolhida de Louis Malle para culpar a história.

A oposição desse texto à denotação na crítica de cinema e à clave psicológica nos filmes sinaliza parte dos objetivos de Cahiers naquele momento. A publicação passava por uma revisão do bazinismo e defendia o cinema moderno como forma de crítica à representação (BAECQUE, 2010, XAVIER, 2005). O elogio à politização do cinema vinha

\footnotetext{
${ }^{2}$ Durante os anos setenta, o termo cinema contestatário era recorrente entre os críticos para abordar os filmes que fingem atacar uma ideologia para defendê-la, através da ocultação da realidade. O objetivo dessa produção seria o de servir aos interesses da classe dominante, sem gerar reflexão crítica ao leitor (AMENGAL, 1975).
} 
junto com a defesa das disjunções no material fílmico. O intuito era aumentar a consciência do público sobre os efeitos de linguagem e demonstrar como a construção ideológica dos filmes tende a reafirmar ideias dominantes e crenças da sociedade (BYWATER; SOBCHOCK 1989). Por esses motivos, a preferência da revista recai sobre as obras que se mostram como discurso e possibilitam ao espectador obter um papel ativo na elaboração de sentido. Tanto a defesa da auto-reflexão no cinema, quanto a atenção dada ao dispositivo cinematográfico como produtor de sentido não eram preocupações comuns só da revista Cahiers du Cinéma, mas da crítica de cinema engajada dos anos setenta como um todo (STAM, 2003).

\subsection{Estereótipos e a preferência pelo naturalismo no cinema}

Vimos acima o quanto os críticos de Cahiers aplicavam ferramentas externas ao campo do cinema. Se nos anos cinquenta, o pilar da primeira fase da revista tinha sido a questão da autoria, na segunda fase, os comentários a Lacombe revelam o diálogo profícuo com a linguística. É exatamente nos anos setenta que uma abordagem bastante teórica, através da semiologia e da revisão do marxismo, torna-se o principal componente de análise fílmica de Cahiers. Essas preferências teóricas da revista para analisar a obra de Louis Malle são mais evidentes num artigo coletivo assinado por Serge Daney, Pascal Kané, Jean-Pierre Oudart e Serge Toubiana (Daney; Kane; Toubiana; Oudart, 1975). O título era emblemático do histórico da revista e transmitia o desejo da publicação de continuar a intervir nos rumos da produção do cinema francês: Uma certa tendência do cinema francês. Essa foi a mesma manchete escolhida em 1954 por François Truffaut (1954) para enfrentar a chamada "Qualidade Francesa", isto é, os filmes de adaptação literária realizados pela categoria de maior prestígio na França: os roteiristas. O artigo é considerado por Antoine de Baceque (2010) ao mesmo tempo uma certidão de óbito da "Qualidade Francesa" e uma certidão de nascimento da Nouvelle Vague. O texto causou grande polêmica no campo cinematográfico, deu grande notoriedade a Truffaut, e inverteu as linhas mestres de análise do cinema para a questão autoral. A escolha do mesmo título em 1975 demonstra o quanto a fase maoista de Cahiers ergueu uma bandeira contra um alvo predeterminado, no caso os cineastas franceses "fascinados" com o nazismo. 
Contudo, como de costume nessa época, a revista não começou o artigo pela análise fílmica propriamente. $\mathrm{O}$ início do texto abre uma discussão teórica sobre o processo abstrato de construção do estereótipo no cinema, procurando criar categorias universais. Na sequência, relaciona-se o estudo ao processo de naturalização dos filmes. Muitos excertos criam contrapontos instigantes sobre os estereótipos, sobre a formação do preconceito e sobre o estigma. Entre os filmes citados, Lacombe Lucien surge como inspiração teórica para discutir o naturalismo e a ideologia. Grande parte dos excertos procura teorizar o funcionamento do estereótipo ${ }^{3}$, mas só aprofundaremos os casos sobre o processo de naturalização, quando os trechos têm aplicação direta ao filme de Louis Malle.

Serge Daney (Daney; Kane; Toubiana; Oudart, 1975) define o estereótipo como uma cilada ou armadilha. O significado proposto diverge do estudo inaugural de Walter Lippman (2008), porque sublinha apenas o sentido negativo. O crítico não interpreta o estereótipo como uma forma de reconhecer imagens mentais criadas culturalmente, nem como uma maneira de facilitar o entendimento do mundo através de simplificações, como fez Lippman. O interesse de ver no estereótipo apenas uma cilada tem relação direta com os comentários sobre a naturalização dos colaboradores no filme Lacombe Lucien. Para Daney, o estereótipo evita o processo de identificação e faz o público posicionar-se contra os personagens nazistas. É através da ideia de "cilada" que Serge Daney liga o estereótipo ao preconceito, através do conceito de naturalização.

Em voz uníssona, Pascal Kané (Daney; Kane; Toubiana; Oudart, 1975) mantém a mesma perspectiva. Ele aprofunda a definição de estereótipo como o encarregado de criar “categorias sociais" que parecem reais, mas são míticas. Graças a esse "fundo mítico”, “o espectador não tem o risco de se reconhecer". Como consequência, nenhum grupo social vivo e consciente de sua identidade irá requerer um personagem estereotipado para si. Nesse trecho é possível vislumbrar mais uma vez uma genealogia com os conceitos desenvolvidos por Roland Barthes (2003) em Mitologias, publicado em 1957. Quando o espectador não consegue ver-se retratado nos personagens da tela porque são falsos, o processo de identificação é paralisado. Como consequência, o público nem imagina o outro, nem se vê retratado. Daí não problematiza seu próprio papel. Dessa forma, esse tipo de filme, segundo

\footnotetext{
${ }^{3}$ Para uma discussão sobre o estereótipo ver o estudo pioneiro de Walter Lippman nos anos vinte (2008), e na área de psicologia, o trabalho de Erving Goffman (1978).
} 
Barthes, não incitaria à ação política. Nos dois casos, a naturalização e a ideologia estão no centro do debate.

A introdução de Cahiers sobre o estereótipo e sua capacidade de assegurar a eficácia dos filmes foi a forma escolhida para analisar o enredo de Lacombe. Num primeiro momento, o cineasta incluiria na ficção duas categorias geralmente ausentes, a do camponês e do jovem. O processo garantiria uma naturalização. Mas se essas categorias sociais conseguem obter dignidade artística, na sequência Malle interdita e exclui os personagens novamente. Para Kané, quem organiza esse processo é o próprio naturalismo, encarregado de contribuir com a segregação e o racismo.

Para teorizar a naturalização, Pascal Kané (Daney; Kane; Toubiana; Oudart, 1975) vai até Roland Barthes (1977). Do livro Roland Barthes por Roland Barthes, o crítico retira uma ideia central para relacionar o que é natural, com o conceito de maioria e minoria. Depois ele adapta os termos ao filme de Louis Malle. Para Kané, cada grupo social constrói uma imagem de si. Contudo, o processo é diferente para as maiorias e para as minorias. As primeiras só têm uma imagem abstrata de si e esse sentimento de ser uma maioria indefinida é criado através do naturalismo, que integra o outro. Sem precisar se ver como grupo, as maiorias não se reconhecem em nenhum estereótipo. Mas elas gostam de colocar as minorias sobre questão e de retratar os marginalizados como conjunto fechado e estereotipado. O processo garante que nenhum grupo reivindique a construção das minorias ${ }^{4}$. Com isso, as imagens do cinema perdem o impacto sobre o espectador. A partir desse trabalho sobre as minorias, os colaboradores franceses em Lacombe parecem apenas uma forma de poder já morto. Com isso, o estereótipo cumpre seu papel de reprimir e negar que o discurso dominante seja baseado numa dialética de exclusão.

Se o estereótipo parece o grande vilão, o responsável pelo processo é o naturalismo. Para explicar o natural, Pascal Kané toma de Barthes (1977) a definição de algo tido como "legal". Estando sempre ao lado das maiorias, o natural cumpre a função de elucidar e trazer uma leitura normativa. Segundo Kané, ao longo da história do cinema, ele se encarregou de excluir algumas representações de categorias sociais. Assim sobraram alguns grupos em polos opostos. No caso dos marginalizados, camponeses e jovens, o naturalismo fez desaparecer a

\footnotetext{
${ }^{4}$ Nesse trecho, Cahiers adapta Roland Barthes (1977). Sem frisar o lado negativo, Barthes repensava duas opções contra o natural para os que estão em situação de minoria. A primeira é a elaboração de um discurso na base do "eu também tenho o direito de....". A segunda opção é devastar a lei majoritária por uma ação transgressiva de vanguarda.
} 
capacidade dessas minorias se verem enquanto grupo. $\mathrm{O}$ processo garante que nenhum espectador consiga se enxergar no estereótipo absurdo de Lucien. A consequência é evitar que uma categoria pense sobre si mesma.

Através de desvios teóricos, esses excertos ligam o estereótipo ao naturalismo e ao preconceito. O conceito cumpre a função de um bode expiatório e é visto como o modo dominante de algo não natural. Como "gênero", o naturalismo tipifica e coloca em prática vários tipos de "segregação" e "racismo". Quando teoriza a construção do discurso sobre as minorias, Kané parece falar do discurso hegemônico. A naturalização surge não só como sinônimo de exclusão das minorias, mas também como a responsável por dotar o filme de um poder invisível e tornar os comportamentos naturais.

O naturalismo não é escolhido por coincidência. Ele permite agrupar Lacombe Lucien e $O$ porteiro da noite (1974) de Liliana Cavani num grupo maior ${ }^{5}$. Um ano depois dos primeiros comentários, Serge Daney amplia seu corpus e observa uma nova tendência no cinema francês. Trata-se dos filmes interessados em dar espaço aos personagens sociais ainda sem representação no cinema. A tarefa é vista como urgente, porque a população não tem uma reserva de imaginário sobre o francês médio. Contudo, a representação do social por meio do naturalismo enquanto forma de filmar e visão de mundo é condenada. Esses diretores não escolhem o realismo, porque teriam de trazer um ponto de vista político. Preferem tipificar, segregar e gerar racismo quando evitam debater a luta de classe.

Nestes textos, o naturalismo não é visto como a busca por uma representação fiel do fato ou como cópia do real (XAVIER, 2005). O que se busca realçar é seu componente ideológico. A revista prefere ressaltar sua relação com o imaginário, com o voyeurismo, com a identificação e com o jamais visto. O fundo teórico dos excertos sobre o naturalismo aponta para o estudo de Roland Barthes (1977). Em Roland Barthes por Roland Barthes, o autor evitou definir o natural como "atributo da natureza física". Preferiu vê-lo como o "álibi arvorado por uma maioria social: o natural é uma legalidade” (BARTHES, 1977, p. 140). Portanto, o trabalho intelectual consistiria em fazer aparecer a lei sobre o natural. Barthes explicava no livro que a ilusão do natural foi constantemente denunciada em Mitologias, Sistema de Moda e $S / Z$.

\footnotetext{
${ }^{5}$ Por exemplo: Dupont Lajoie (1975) de Yves Boisset, Os violinos do baile (1974) de Michel Drach, La coupe à dix francs (1975) de Philippe Condroyer.
} 
Ainda em 1957, Barthes inaugurou uma linha mestre de pensamento para a crítica engajada com o livro Mitologias. A denúncia do naturalismo propunha uma crítica ideológica da linguagem da cultura de massa e o desmonte do processo de conversão da cultura pequeno burguesa em natureza universal. As coincidências com a nova fase de Cahiers não param por aí. No livro, o autor analisa o enredo dos filmes para demonstrar a correlação entre a forma e a formação ideológica. Como o próprio Barthes (2003) demonstrou, essa técnica tornou-se mais sutil no pós-68, mas o princípio norteador para analisar Lacombe era o mesmo.

Na nova fase de Cahiers, Barthes torna-se figura presente como entrevistado por causa da preferência teórica da revista pela linguística, pela semiologia, etc. Como parte desse processo, Pascal Kané (Daney; Kane; Toubiana; Oudart, 1975) adapta os comentários de Barthes sobre o naturalismo e sobre o processo de identificação com os personagens da tela. Em 1957, Barthes explicou como a ideologia burguesa impedia que a visão de mundo parecesse ideológica. Quando os personagens apresentados são falsos, o público não consegue colocar-se no lugar do outro. A tendência é ver a imagem pela chave do exotismo, ignorar o outro da tela ou simplesmente "tapar" os olhos. Foi provavelmente desse trecho do livro que Cahiers relacionou a capacidade do naturalismo de impedir a autoanálise do grupo, através da falta de identificação com os personagens na tela.

\subsection{A moda retrô do cinema francês}

A primeira acusação direta a Lacombe Lucien não foi a de pertencer à nova safra do naturalismo francês, mas à onda retrô (BONITZER, 1974a). O termo designava os filmes reacionários, simpáticos ao fascismo ou apenas fascinados por ele. Se a produção criava uma nova imagem do francês médio, e representava um período recente da história, a moda retrô teria um racismo latente ao abordar o estrangeiro ou o típico francês marginalizado. O perigo do ponto de vista ideológico seria o de aglutinar política e erotismo no cinema.

Serge Daney aprofunda esse tema. Ele relaciona o surgimento da onda retrô com o declínio da ideologia do gaullismo, com a morte de Pompidou e com a crise do discurso humanista da burguesia (DANEY, 1974d). A safra teria demonstrado que o cinema dominante agora continha as cores do real, sem esquecer categorias sociais. Por um lado, Lacombe 
Lucien estava ancorado na História, sem trazer uma imagem tradicional da resistência. Mas por outro lado, Louis Malle enquanto "cineasta burguês" era criticado por incorporar os componentes da onda retrô, isto é, tematizar política ao lado de sexo. Nesse processo, segundo Daney, haveria um esvaziamento do conteúdo da sexualidade, mantendo o monopólio de um discurso educativo e normativo sobre sexo.

Daney quer problematizar que os filmes reacionários, simpáticos ou fascinados pelo fascismo são incapazes de lutar contra o sistema. Eles atuam no lado inverso: retratam heróis conscientes com mensagens claras, edificantes, numa linha política precisa e didática. A consequência é mostrar nos filmes somente os marginalizados ou estrangeiros como articuladores do racismo e do fascismo.

Vendo Louis Malle como artista de ideologia burguesa, Serge Daney envereda por uma perspectiva marxista em sua argumentação quando diz: as "contradições de classe em Malle não são nada além de contradições, tornadas assim acidentais, particulares e ahistóricas” (DANEY, 1974d). Se a tensão entre Lucien e a família judia é, no fundo, social, Daney considera que Louis Malle apaga esse critério político. Assim "a impunidade e a confrontação de classe" aparecem somente "em termos de rivalidade pacífica", isto é, são convertidas na alternância entre a busca de um pai e a rivalidade do garoto em relação a essa mesma figura paterna, representada no pai judeu "substituto". Para Daney, com esse subterfúgio, a luta social é apagada e convertida apenas numa prova da eterna ambiguidade do homem.

$\mathrm{O}$ atrito com o filme de Louis Malle ocorre porque exatamente o conflito de classe não foi abordado. Daney (1974d) defende um cinema que deixe o público alerta sobre a hegemonia do pequeno burguês. Se Louis Malle não teria feito isso, pelo menos a trama de Lacombe trouxe sujeitos sociais ausentes na representação do cinema, como o camponês e a juventude, admite o crítico. Nesse sentido, o filme vai contra o estereótipo e a fórmula da luta heroica da resistência francesa, monopolizado pela imagem do gaullismo e pelo partido comunista francês. Por esses motivos, para Daney, a temática de Lacombe diz respeito "à memória da luta popular”. Mas o erro de Malle foi realçar a questão da erotização do poder. Indiretamente Daney (1974d) aproveita o filme para lembrar que inexiste na produção corrente "uma perspectiva de esquerda para se contrapor a da classe liberal que Malle representa". Para contestar essa visão de mundo, seria preciso focar, por exemplo, no ponto de vista do professor da escola de Lucien, que faz parte da Resistência. Daney explica que essa 
questão carece de teorização e termina o artigo com uma indagação: "como construir uma ficção (uma história) de uma perspectiva que não seja o de saber absoluto sobre a história?" Isto é, como trazer ao cinema esses sujeitos sociais ausentes, como o camponês e o jovem, com suas lutas políticas? Observa-se que a discussão envereda pelo papel do cinema como instrumento de fortalecimento da luta social.

Daney (1974d) comenta como o filme evitou abordar Lucien como vilão. Assim seu comportamento é explicado pela seguinte fórmula: "há com certeza carrascos e vítimas em cada um de nós”. Esta frase representa a máxima da onda retrô e é encarregada de ocultar ao público que as ideias nunca são naturais. Através do manto da psique indecifrável de Lucien, o ponto de vista burguês conseguiria transformar suas concepções de mundo em algo que pareça natural, sem que seja necessário explicitar sua perspectiva política no corpo do filme. Para Daney, a mensagem de Lacombe é nociva porque permanece latente:

O discurso implícito do filme (pelo uso da conotação) desencadeia em torno do espectador um delírio interpretativo que o faz esquecer a pobreza e a banalidade da lição. Malle (...) não é o cineasta do inexplicável, ele é o cineasta do inexplicitado. O inexplicitado não é o contrário da positividade, é uma forma (...) dominante. (DANEY, 1974d).

Com essa armadilha, o nazismo parece vir da perversão ou do instinto humano. Dessa forma, ele consegue ser mostrado como algo natural. Segundo o autor, sua força estaria na capacidade de mobilizar forças ocultas em estado latente nas pessoas (DANEY, 1974b). Ao longo do texto, Serge Daney (1974d) repensa o mecanismo que torna crível essa crença naturalista. O que seria importante para Louis Malle? - se pergunta o crítico: "Que Lacombe não interiorizou nada, não memorizou nada, que ele pode carregar enunciados, cujos sentidos ele não entende ou é incapaz de assumir?" Para o cineasta, o personagem é um "inconsciente, bárbaro, incapaz de pensar sobre processos históricos e agir através deles". Com essas formulações, a abordagem política do nazismo permanece oculta. Daí o comportamento de Lucien também pode parecer natural ou instintivo. O incômodo de Daney ocorre porque Louis Malle não explicita seu discurso sobre um tema político, adotando uma solução explicativa atrelada à psicologia. O responsável por inocentar Lucien e esconder sua visão de 
mundo, portanto, cabe à naturalização. Graças a ela, o espectador acredita na possibilidade de encontrar toda a verdade sobre um personagem.

Pensando nesse espectador, Cahiers desenvolve uma linha argumentativa com foco na ação de um público extremamente proficiente. O intuito é revelar como certa visão de mundo [ou ideologia latente] se faz presente no filme e o quanto a análise não deve permanecer apenas no enredo. Com esse objetivo em mente, a revista traça uma correlação entre o personagem, a classe social do cineasta e a visão de mundo expressa pelo filme. Esse método estava em alta no período e era o pilar de sustentação da crítica marxista (EAGLETON, 2011). Vendo as obras artísticas como produto da história, os artigos relacionam a linguagem e a mentalidade social de cada época. Assim a ideologia incrustada de sentidos acumulados ao longo dos séculos tornava-se um termo chave da esquerda (STAM, 2003), enquanto a crítica trazia para o debate o papel ideológico dos meios de comunicação. O propósito era localizar os valores dominantes do sistema engendrados pela ideologia.

A contra proposta de Cahiers é apresentada edições depois por Serge Daney (1974d). A onda retrô conseguiria evitar o debate do presente, porque obriga o público a escolher entre dois opostos num campo de inimigos situados no ontem. A sugestão da revista está centrada na ação do espectador, que pode recusar um dos termos apresentados. Quando o público se indaga sobre quem é o responsável por colocar as questões do filme, ele consegue trilhar os caminhos da enunciação. Assim a théorie du 'choix obligé' opõe um sistema a outro, e revela o funcionamento dos objetos enquanto dispositivo com suas técnicas de manipulação.

A preferência da revista recai, portanto, aos filmes modernos que apresentam a luta política na forma cinematográfica. Se Lacombe aparece com frequência nos artigos de Cahiers, no polo oposto a revista vai defender Eu, Pierre Rivière que degolei minha mãe, minha irmã e meu irmão (1976) de René Allio ${ }^{6}$. A obra de Allio conjugaria as qualidades opostas. O personagem funcionaria como uma possibilidade de contra-argumentação para o Lucien primitivo, que faz o papel do estúpido da história. Rivière pode não ter conhecimento, mas tem "discurso" e "memória". Afinal, "alienado não significa ahistórico", relembra o crítico (Daney, 1974d). Portanto, o comentário em torno dos dois filmes demonstra a preferência da revista pelo cinema moderno e pela incorporação da luta social como parte da motivação política dos cineastas.

\footnotetext{
${ }^{6} \mathrm{O}$ filme teve a presença da equipe editorial de Cahiers: Pascal Bonitzer e Serge Toubiana colaboraram com o roteiro.
} 


\subsection{O outro lado da moeda: a dissonância aplicada por Michel Foucault e Marc Ferro}

As indagações acima lançadas por Serge Daney surgem após a entrevista com Michel Foucault e Marc Ferro. Nesses espaços, o pensamento uníssono dos críticos de Cahiers sobre Louis Malle encontra a divergência de intelectuais externos ao campo do cinema. A presença desses dois teóricos representa uma nova fase de Cahiers no pós-68. Quando o debate cinematográfico era feito num nível cultural mais amplo, a publicação abriu uma discussão que extrapolou os limites do cinema. Nesse novo contexto, filósofos, linguistas, historiadores eram presença constante entre os entrevistados, como Michel Foucault, Marc Ferro, Roland Barthes, Claude Levi Strauss. Nessa fase, houve uma queda vertiginosa de público, em relação à fase áurea dos anos cinquenta, devido à complexidade e densidade dos artigos, que nem sempre analisavam os filmes em pormenores. De maneira geral, os textos, sempre longos e escritos de maneira complexa, não facilitam a leitura. As frases costumam ser encadeadas ao longo de um parágrafo com um único ponto final, exigindo que o leitor costure significações não só entre as sentenças, mas também entre vários artigos para a compreensão do sentido.

A entrevista com Foucault (1974) é centrada sobre a moda retrô, especialmente sobre Lacombe Lucien. A motivação do texto é a pesquisa do filósofo sobre a construção da memória popular em oposição à tradição oficial ${ }^{7}$. A motivação geral da revista é indagar a razão pelas quais a onda retrô evita o tratamento do fascismo em termos históricos, preferindo o contorno da fascinação e da erotização. Foucault (1974) responde que a história recente da França nunca foi contada fora das fontes oficiais. Foi relegada ao relato baseado no Gaullismo, "única forma de reescrever o nacionalismo em termos honrosos". Ao narrar a história da França sobre outro ponto de vista, Lacombe revela que nem todo o país era antifascista.

O novo olhar do entrevistado sobre o filme de Louis Malle passa pela constatação de que o nazismo não foi uma ditadura em sentido clássico, nem a continuação do poder da burguesia. Ele só existiu graças a uma população que se tornou responsável pelas atividades de repressão, controle e ordem. Portanto, o poder foi delegado à população e a certas pessoas

\footnotetext{
${ }^{7}$ Parte da entrevista com o filósofo dedica-se a comparar a construção de Lacombe Lucien e a de Pierre Rivière, cujo livro foi tema de pesquisa de Foucault.
} 
à margem. "Quando uma pessoa entra para a SS, ela pode matar seu vizinho, se apropriar da mulher e da casa dos outros. E é aí que Lacombe Lucien é interessante, porque ele mostra esse lado bem", diz Foucault.

Para o filósofo, o erótico possibilita uma reconciliação do anti-herói. Assim, o “excessivo poder" dado ao personagem transforma-se em amor. "O amor toma o excesso de poder que é convertido numa nudez rural". Por relações deformadas, Lucien ama France e isso o restabelece como personagem. Explicando de maneira detalhada a construção do filme, Foucault demonstra como essa ligação traz consigo o problema histórico de apresentar o nazismo via erotização:

Eu acho que o erótico em Lacombe, o aspecto passional tem uma função que é fácil de localizar. É basicamente um modo de reconciliação do anti-herói, de dizer que ele não é tão anti-herói como tudo isso. Se todas relações de poder são distorcidas por ele, e ele reproduz a ineficácia, por contraste, quando pensamos que todas as relações eróticas são deformadas, uma relação verdadeira se descobre, ele ama a moça. Por outro lado, há um tipo de maquinário de poder que permite a Lucien mais e mais se tornar um tipo de louco. Mas por outro lado tem um maquinário de amor que parece seguir o mesmo padrão, que parece ser distorcido, e trabalha na direção oposta e restabiliza Lucien no final com a nudez bela do garoto vivendo no campo com a moça. Existe um tipo de antítese entre o poder e amor. O poder tem um custo e uma carga erótica. $E$ isso nos traz um problema histórico, como o nazismo que é representativo do patético, como pode ser um referente absoluto do erotismo? Um imaginário erótico está sendo feito sobre o signo do nazismo (FOUCAULT, 1974).

Vendo o erótico no filme muito além das categorias de repressão, Michel Foucault considera que Lacombe Lucien traz o debate sobre a memória das lutas populares somente no passado. Se esse tipo de memória nunca encontrou seu espaço de discussão, o tema permite interpretar o presente. Sem ver Louis Malle como cineasta burguês, Foucault propõe uma interpretação bem mais complexa da ideologia, quando demonstra a correlação entre nazismo e a participação da sociedade.

Exercendo a pluralidade de opiniões, Cahiers abriu espaço não só para a voz dissonante de Foucault, mas também para Marc Ferro. Na entrevista, o historiador não trata somente do filme de Louis Malle e traz uma visão positiva da onda retrô por causa de sua ligação com o "grande questionamento das ideias e das certezas, que é a marca de nosso tempo" (FERRO, 1975). Segundo ele, o desenvolvimento do audiovisual gerou um 
questionamento da cultura paralela sobre a "legitimidade e o funcionamento dos saberes e dos comportamentos tradicionais". Por causa disso, nosso tempo realça a informação, o confronto e a incoerência entre as atitudes individuais e coletivas. Ao contrário da revista, Marc Ferro declara que apreciou muito Lacombe Lucien porque:

\begin{abstract}
Malle mostrou admiravelmente que, enquanto uma sociedade funcionar como a nossa, ela produzirá seus Lacombe Lucien. Crítica profunda que reconsidera todo um discurso sobre o fascismo e que é uma análise a ser continuada: quem se aventurará a ela? Tentativas desse tipo encontram viva ressonância porque nossa sociedade quer absolutamente saber como ela funciona, mas o saber tradicional está bem ali em seu lugar, vigilante, para impedir isso. Ora a história deveria fornecer uma resposta, mas frequentemente a serviço das instituições, ela se contenta em distribuir o sonho, portanto sob a máscara do cientificismo. Ela se recusa demais a explicar o presente, daí a onda, fugaz é verdade, da sociologia. É urgente que a história se torne, finalmente, uma ciência viável (FERRO, 1975).
\end{abstract}

Se a história não respondeu às perguntas sobre o passado recente, há uma nova tendência a partir do discurso do fascismo. Para Ferro, esse fenômeno está relacionado ao crescente questionamento da legitimidade das ideias e das certezas dos anos setenta. Trata-se da possibilidade dos aparelhos audiovisuais modificarem nossa relação com a história. Abrindo novas perspectivas de pensar o filme, como fez Foucault, Ferro não estava preso às ferramentas atreladas à politização crescente do campo do cinema. Preferiu problematizar a relação entre documento, cinema e história ao longo da entrevista.

\title{
3 CONSIDERAÇÕES
}

O que Cahiers exigia de Louis Malle, afinal? Primeiro, desmontar o sistema de representação nazista. Depois, realçar o questionamento da formação discursiva do personagem pelo ponto de vista do cineasta. Afinal a luta política deve aparecer na enunciação, na escolha dos temas e na forma cinematográfica. A revista tem nessa época a crítica como instrumento de transformação social. É por isso que Cahiers condena a falta de questionamento sobre a formação discursiva de Lucien. A publicação vê nessa lacuna uma consonância entre a ideologia burguesa do diretor e os modos de visibilidade do nazismo. 
A crítica engajada daquele momento tinha uma preferência pelos filmes que aumentavam o espaço entre sua própria formação discursiva e a dos personagens representados na tela. Esse tipo de filme seria mais adequado para demonstrar a luta de classe, porque o nível mais alto de opacidade permitiria ao leitor buscar os significados não revelados, via conotação. Portanto, Cahiers opta pelo cinema que enfatiza o discurso por detrás dos filmes, isto é, se trata de uma defesa do cinema moderno com as disjunções fílmicas. Se o cinema não é a verdade, mas representação, os filmes devem realçar o processo de revelação de uma visão histórica.

Lacombe Lucien estaria do lado oposto. Para Cahiers, Louis Malle tentaria gerar uma crença na possibilidade de mostrar toda a verdade sobre um personagem. Para revelar ao público como a crença na ideia de verdade determina relações de poder, a partir da naturalização do discurso, a revista utiliza diversos critérios metodológicos daquele momento. Como vimos, todas estas formas de análise corriam juntas nos textos. Mas ao seguir esse percurso analítico de maneira detalhada é possível acompanhar como as teorias eram mobilizadas para examinar os filmes. Decorre desse processo a complexa articulação metodológica entre quadros teóricos diferentes ou complementares.

Naquele período, Cahiers trazia duas formas de análise fílmica. Desde 1969 havia uma nova linha que era inaugurada com o editorial de Jean-Louis Comolli e Jean Narboni (1969) denominado "Cinema, ideologia, crítica". Os filmes eram agrupados em três grupos. Enquanto uns disseminam a ideologia, outros se opõem a ela através de evidente desconstrução do sistema de representação. Uma terceira categoria faz parte da produção industrial, mas mesmo assim realiza uma desmontagem do sistema ideológico, quando transgride e denuncia a intenção de seus autores na trama fílmica. Assim o trabalho cinematográfico possuía graus diferentes de fissura: desde o ataque frontal ao sistema até uma subversão dissimulada a partir de disjunções fílmicas que expõem os limites da ideologia oficial sob uma aparente coerência formal.

Porém para analisar Lacombe Lucien a metodologia da revista não procurou encontrar fissuras e lacunas no material fílmico. O parâmetro inicial de análise começou pela ligação entre o cineasta, a classe social e a visão de mundo expressa pelos filmes. Trata-se de um método de análise da crítica materialista para observar como os cineastas disseminam a ideologia. Para os diretores "burgueses”, como Louis Malle, o objetivo era desmistificar o conteúdo latente dos filmes. O critério não era só de Cahiers. Ao longo dos anos sessenta e 
setenta, a crítica interessada em desconstruir o caráter ideológico dos filmes era utilizada em diversas revistas de esquerda ao redor do mundo (BYWATER, SOBCHACK, 1989). Como consequência, buscava-se evitar um olhar purista sobre o cinema, trazendo o debate em direção à historicização do campo artístico (BOURDIEU, 1996) ${ }^{8}$. No caso de Lacombe, o debate revelou a vitalidade gerada pela junção entre as análises teóricas.

Se esse tipo de análise era comum nas publicações engajadas, nem todas as revistas de esquerda veem Lacombe de maneira negativa. Embora não seja nosso intuito retomar a recepção crítica do filme, a título de ilustração retomamos um comentário de Positif para demonstrar como o debate sobre Lacombe na crítica engajada podia tomar outros rumos. $\mathrm{O}$ crítico Michel Sineux (1974) não desconsidera o cineasta por razões ideologias, ligadas à crítica marxista. O princípio norteador do artigo dele em Positif é analisar a mise en scène de Louis Malle. Para o crítico, a frieza e a insensibilidade do cineasta são responsáveis pelo estilo de Malle. Deixando de lado a motivação política, a origem social do cineasta não importa para Sineux (1974). Ao contrário, como burguês, Malle pôde falar como representante de sua classe. Se o artigo de Positif destoa das características mais conhecidas da publicação nos anos cinquenta, há um deslocamento da discussão política para a mise en scène, exatamente quando este conceito sofria um grande revés no período (STAM, 2003).

Era exatamente nessa época que o uso das teorias externas ao campo do cinema crescia em Cahiers, trazendo uma contribuição à análise fílmica no caso de Lacombe, através das teorias da enunciação, da semiologia, da revisão do marxismo e do estudo sobre os estereótipos no cinema. Contudo, cabe um adendo sobre a análise da composição psicológica do personagem, sobre a representação da luta de classe e sobre o imperativo do cinema moderno. Se Cahiers opôs-se à crítica psicológica de Lucien, por uma suposta fuga do sentido político, a utilização dessa perspectiva de análise aplicada ao personagem permitiu trazer outras significações sobre a luta de classe de uma juventude rural em relação ao poder consolidado dos franceses. Nesse sentido, emerge um sentido político de microesferas do poder que chega a uma chave explicativa sobre Lucien, exatamente através da psicologia. Por fim, resta ampliar o entendimento sobre o questionamento da naturalização como ocultação da ideologia. Nesse caso, os imperativos políticos e a defesa da disjunção do material fílmico não abriram espaço para aceitar uma narrativa que fugisse ao cinema moderno. Dessa forma, parte

\footnotetext{
${ }^{8}$ Se de um lado o debate em torno da mise en scène traz os critérios artísticos por si só, Pierre Bourdieu realça os conflitos sociais, as tensões históricas e as condições de produção. Longe de procurar uma essência universal, o autor insiste na necessidade de historicizar as obras, explicitando os cânones utilizados.
} 
do questionamento a Lacombe tem como origem a falta de problematização do próprio modo de produção.

Os comentários não buscam desqualificar o método de análise da crítica de cinema, uma vez que as significações construídas pelos críticos independem do próprio filme. O conteúdo dos textos é sempre móvel e flutuante, mas auxilia acima de tudo a compreender melhor os mecanismos de significação do cinema. Mesmo que a relação entre ideologia, classe social e visão de mundo dos filmes não seja utilizada com vigor pelo ambiente cultural atual, os textos de Cahiers sobre Lacombe revelam uma vitalidade impar de pensamento. A revista conseguiu extrair uma grande quantidade de questões de fundo teórico e desenvolveu outros critérios de análise fílmica, muito além do que era feito pela crítica de cinema especializada.

\section{REFERÊNCIAS}

AMENGUAL, Barthélemy et al. Cinema, arte e ideologia. Porto: Afrontamento, 1975.

BAECQUE, Antoine. Cinefilia - invenção de um olhar, história de uma cultura: 1944-1968. São Paulo: Cosac Naify, 2010. [2003]

BARTHES, Roland. Mitologias. Rio de Janeiro: Difel, 2003 [1957].

. S/Z. Buenos Aires: Siglo Veintiuno Editores Argentina: 2004.

Roland Barthes por Roland Barthes. São Paulo: Cultrix, 1977 [1975].

BONITZER, Pascal. Histoire de sparadrap. Cahiers du Cinéma, n. 250, maio 1974.

BONITZER, Pascal ; DANEY, Serge. Fonction Critique: histoire d'enoncer. Cahiers du Cinéma, n. 250, mai. 1974a. 
BYWATER, Tim; SOBCHCK, Thomas. Introduction to film criticism. New York: Longman, 1989.

COMOLLI, Jean ; NARBONI, Jean. Cinéma/idéologie/critique. Cahiers du Cinéma, n. 216, out. 1969, p. 11-15.

DANEY, Serge. Anti-rétro (suite). Cahiers du Cinéma, n. 253, out./nov. 1974.

1974a.

Même pour Pariscop 3, il existe des filmes politique. Cahiers du Cinéma, n. 250, mai.

Fonction critique (fin). Anti-retro (suite). Cahiers du cinema. n. 253, out./nov. 1974d.

Un film est toujour positif pour quelqu'un. Cahiers du Cinéma, n. 250, mai. 1974b.

Qui dit quoi, mais où et quand? Cahiers du Cinéma, n. 250, maio 1974c.

DANEY, Serge; KANE, Pascal; OUDART, Jean-Pierre; TOUBIANA, Serge. Une certaine tendence du cinéma français. Cahiers du Cinéma, n. 257, mai.jun. 1975.

EAGLETON, Terry. Marxismo e crítica literária. São Paulo: Unesp, 2011 [1976].

FERRO, Marc. Cinéma et histoire: entretien avec Marc Ferro. Entrevista concedida a Serge Daney e Ignacio Ramonet. Cahiers du Cinéma, n. 257, mai. jun. 1975.

FOUCAULT, Michel. «Anti-retro: entretien avec Michel Foucault ». Entrevista concedida a Serge Toubiana e Pascal Bonitzer. Cahiers du Cinéma, n. 251-2, jun./ago. 1974.

GOFFMAN, Erving. "Estigma e identidade social”. In: Estigma. Rio de Janeiro: Jorge Zahár, 1978.

HILLIERS, Jim; BROWNE, Nick. Cahiers du Cinéma: 1960-1968: New Wave, New Cinema, Reevaluating Hollywood. v. 2. London: Routledge, 1996.

LIPPMANN, Walter. A Opinião pública. Rio de Janeiro: Vozes, 2008 [1922].

STAM, Robert. Introdução à teoria do cinema. Campinas: Papirus, 2003 [2000]. 
SINEUX, Michel. Le hasard, le chagrin la nécessité, la pitié (sur Lacombe Lucien). Positif, n. 157, mar. 1974.

TRUFFAUT, François. « Une certain tendence du cinéma français » Cahiers du cinema, n. 31, jan. 1954, pp. 15-29.

WILSON, David. Cahiers du Cinéma: 1973-1978: History, Ideology, Cultural Struggle. London: Routledge, 2000.

XAVIER, Ismail. O discurso cinematográfico - a opacidade e a transparência. São Paulo: Paz e Terra, 2005.

Doutora em Meios e Processos Audiovisuais (ECA-USP). Desenvolve pesquisa de Pós-Doutorado na UFSCar (PNPD/CAPES), onde é professora do Programa de Pós-Graduação em Imagem e Som. Autora do livro Crítica de cinema e repressão (Alameda/Fapesp, no prelo). Integra o comitê editorial da revista Significação. É também uma das co-organizadoras do livro Cinema e história: circularidades, arquivos e experiência estética (Editora Sulina, 2018).

\section{@ $\odot \odot \odot$}

Esta obra está licenciado com uma Licença

Creative Commons Atribuição-NãoComercial-CompartilhaIgual 4.0 Internacional 